\title{
Survey on improve performance of WSN using TDMA
}

\author{
Mahesh Vhatkar \\ University of Pune, Department of Computer \\ Engineering, K.J College of Engineering and \\ Management Research Pune, India
}

\author{
Deepak Mehetre \\ University of Pune, Department of Computer \\ Engineering, K.J College of Engineering and \\ Management Research Pune, India
}

\begin{abstract}
Wireless sensor networks are very useful in almost all types of applications to make our life more and more easy. Most of work in WSN is based on load balancing to conserve energy and energy related a problem because life of node is depends on life of battery. With energy efficiency balancing of load is also required for proper working of the system .Qos requirements are also important .This paper provides a survey of use of TDMA to meet above requirements such as providing energy efficiency and providing QoS. We also compared these protocols with respect to Energy awareness and Qos requirements. At last we have provided our conclusion on this work and also commented about future work which will possible.
\end{abstract}

\section{General Terms}

QoS ,Performance of WSN

\section{Keywords}

Wireless Sensor Network, TDMA, Load balancing, Energy efficiency, Sensor Nodes, Clustering.

\section{INTRODUCTION}

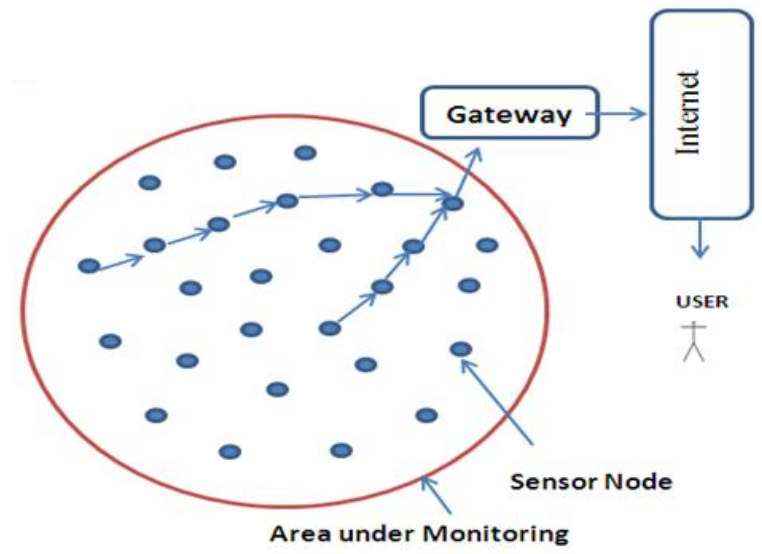

Fig 1 : General Architecture for Wireless Sensor Network

Wireless Sensor Network is made up of number of sensor nodes placed in the area under monitor .each sensor node is provided with different types of sensors for collecting information from the environment .This information is processed at the sensor node and forwarded towards sink node .This sink node can send quires for different types of data to the sensor nodes and finally user can access this data through the internet as shown in fig 1 .Unlike any wired network WSN has many limitations. WSN is applicable in all areas of our life from battle field monitoring to the civil applications such as fire detection and so on We should kept number of objectives before development of any WSN ,objectives are depends on application of WSN .If we are developing WSN for harsh and hostile environment then energy efficiency must be considered because any sensor node operates on battery and it has minimum life time and mostly it is not possible to replace it.so to improve life time of any network energy efficient protocols must be developed .TDMA is mostly used to achieve these types of requirements because it is contention free and there is minimum loss of packets and retransmission.

WSN is mostly used today for variety of applications .Arrangement of network is different for different domain according to the requirement .WSN is very useful in applications such as monitoring of environment, in industrial automation ,for development of monitoring system for crops and so on there is no limit for application of WSN .Energy constraints must be considered while design of any WSN because of we provide energy to the WSN device by using battery .In most application with energy constraints some applications requires to consider other constraints[1] also such as delay minimization, low latency and collision avoidance. Most contention based MAC protocols such as BMAC are not useful to provide these requirements, so we can use TDMA based protocols, for using TDMA we want algorithm for time slot allocation. Here time is divided into different slots each node will be provided with communication slots so there is minimum possibility of collision. For dynamic nodes decentralized slot allocation is very useful [1].fig 1 shows typical structure of any Wireless sensor network.

QoS is also another important point similar to the energy efficiency because in any real time application we should provide better quality of service such as minimum latency, guaranteed delivery of data and reliability of information point very important to improve for improving performance of any WSN system. Congestion control is one of the important QoS in WSN .Which QoS have to be provided is depends on the application we are using, so quality of service requirements are different for different for different applications [2].when more than one sensor nodes tries to send data on same radio channel then there is possibility of contention ,because of contention there is reduction in QoS, waste of energy and bad effect on the total performance of the system[3].According to written in literatures TDMA and CSMA are mostly used to share common medium. TDMA is more useful MAC protocol to avoid collisions in the network than CSMA in any Wireless Sensor Network. TDMA is used because of it requirement of synchronization and application specific scheduling. If schedule time of any algorithm is to long it will reduces the system performance, reduces QoS, increased energy waste, and waste of bandwidth, so scheduling time should be minimum as possible [3] Lot of research has been done during last few years to use of TDMA to reduce contention in the system. We can solve medium access problem by using CSMA and TDMA protocols .Performance of CSMA is low in high data rate applications. We know CSMA technic sense the medium before any transmission of data, this is not effective method when two nodes tries to send data at the same time, because of that 
CSMA has low performance in case of correlated contention [4].

TDMA is more suitable WSN protocol for applications having high data rate and effective channel utilization. We can divide TDMA scheduling in terms of static and dynamic scheduling .static scheduling provides schedule of smaller length and it is helpful in improving bandwidth utilization. On the other hand dynamic scheduling provides schedule in very short period of time but it is less useful in bandwidth utilization. When network topology is same for long period time then we can use same static schedule for long time but mostly in real applications it is not possible because network always changes its topology in case of any node failure or when node is sleeping for energy saving purpose [4].

We know that large amount of power is consumed for data transmission and reception in any WSN node. So it is better idea to sleep node when there is no any data for sending or receiving purpose. So we can minimize energy consumption by switching of transceiver. Medium Access Control mechanism can decide how transceiver can work .CSMA method is best for Medium Access Control but CSMA provide low bandwidth utilization due to the collision. So for better bandwidth utilization TDMA is best [5]

In case of real time applications quality of service is also very important. So design of MAC protocol should such that to provide QoS in addition to energy efficiency [9]

This paper provides deep survey of work using TDMA in WSN .This paper is also useful for new researchers to start their work and to provide them basic idea of about application of TDMA technology in WSN

\section{WHY TO USE TDMA}

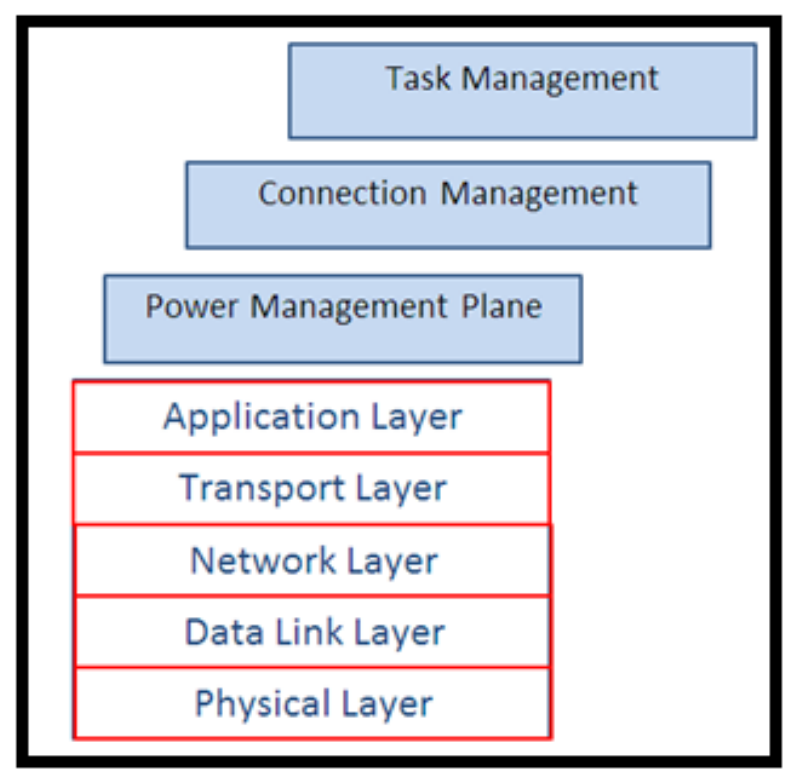

Fig 2 : Protocol Stack for WSN

We know that in WSN all the nodes communicates with each other and sends information to the base station using same communication medium. We know that WSN is very different from traditional wireless LAN because WSN has many limitations and constraints which we have to consider, such as limited energy, limited bandwidth, limited processing power and limited storage .Because of that we cannot apply MAC protocols of Wireless LAN such as Bluetooth directly to the WSN.
The most useful protocols are based on TDMA i.e. time division multiple access. In TDMA based Medium access time is divided into number of time slots and each node is provided with its own time slot. Because of this node can communicate by using only its own time slot. Medium access is performed at the Data link layer with other responsibilities medium access is also important responsibility of data link layer.In fig 2 we have provided protocol stack for WSN.

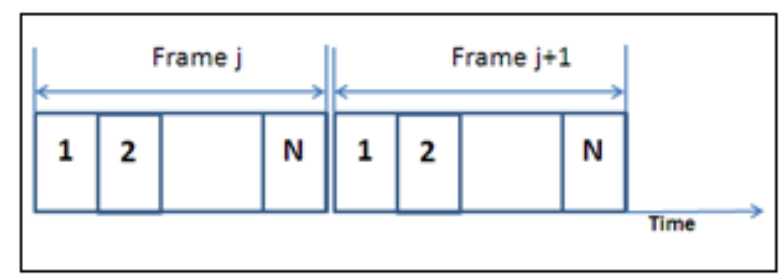

Fig 3 : TDMA frame

In order to use TDMA we require proper time synchronization between sensor nodes .we can use any suitable synchronization protocol for that purpose .TDMA is very useful because node can use all the available bandwidth to send and receive data with highest data rate.

Here time is divided into number of time slots. and by using $\mathrm{N}$ number of time slot one frame is created .each node is provided with single time slot in this frame as shown in figure 3 . Here we have $\mathrm{j}$ for representing single frame and $\mathrm{j}+1$ indicates new frame

In TDMA each node will provided with communication slots so there is minimum possibility of collision. In literature, (TDMA)time division multiple access and (CSMA)carrier sense multiple access are mostly used methods for accessing medium in any WSN but CSMA is mostly subjected to collision and contention. At other side TDMA is very useful to avoid contention and to provide energy efficient WSN because of that TDMA is widely used for medium access purpose .but use of TDMA requires strong time synchronization. To provide clock synchronization there is lot of work is in progress [3]. TDMA is very useful for high data rate application than CSMA.We can use static or dynamic TDMA scheduling according to requirement of our application and data rate we have to handle [4].

\section{RELATED WORK}

Author Domenico De Guglielmoetal presented slot allocation algorithm based on TDMA which works in decentralized way which is self-adaptive and localized, each device only use local information and based on this information slots are arranged, they proved that their solution is better than existing works with the help of simulation. According to the author initially work is provided for single hope and the work can be improved for multi hope communication [1].work cannot use any information provided by central sink node for purpose of slot allocation instead each node is capable of selecting its own time slot to transfer information. Slot is divided for packet transmission and for acknowledgment purpose. Collision is avoided because each node is provided with different slots. To avoid contention node uses fake data to send for particular time slot, if node will success then node will obtain this time slot for farther data transmission otherwise node will repeat same process for next time slot this technic is very useful to reduce latency according to the author .Discrete Time Markov Chains used to perform analysis of system. Centralized method of slot allocation is not useful for dynamic environment where nodes are added 
and removed dynamically node with collision experience waits for some time and try again, to avoid collision of node random back off method is used[1]. Successful node can get the slot and during next time this node will get highest priority by setting its back off time to zero. If node fails node will try for next time slot, so this work is very useful for collision avoidance and energy consumption [1].According to author Viveket.al there is lot of effect of congestion and traffic on the performance of the system. How different MAC protocols perform in different situations such as heavy traffic and network with congestion is also explained. Network simulator 2 is used to perform simulation. Author proposed FMAC protocol it is based on both TDMA and CSMA medium access protocol, so FMAC protocol is a hybrid protocol .According to work [2] Packet delivery ratio of FMAC is better up to 48 - 91 percent than 802.15.4. MAC protocol .Time required to send data from source to destination node is less than TDMA and CSMA according to the result provided by the author. QoS parameters are shown in simulation and performance of FMAC is shown against any single protocol such as CSMA, so according to this paper it is better to use hybrid protocols instead of using any single MAC protocol for improving performance of communication in WSN [2].Ashutosh Bhatia et.al, he proposed a new protocol named RD-TDMA i.e. Randomized Distributed TDMA, most of present TDMA protocols are not sufficient to improve performance. According to author Randomized Distributed TDMA generates possible schedule in very short duration of time. Castalia simulator is used to show the performance of the system. This algorithm is proposed to minimize scheduling time of the network. According the author TDMA based Medium access mechanisms perform better than the contention based protocols, it provides improved reliability utilization of channel, and minimized power requirement mostly in case of applications where data ret is very high in (WSNs). Most of the. We can classify TDMA protocols in to the static and dynamic category [3].

The primary purpose of static TDMA is very useful to provide schedule of smaller length but time required for scheduling is high because of that it is not useful for WSN applications where topology of network changes frequently and dynamically. At other side dynamic TDMA can generate schedule in very less time but it cannot work well in terms of schedule length. This author has tried to combine strong side of both static and dynamic TDMA mechanisms, their proposed work creates schedule of smaller length and also creates schedule in very short period of time. They have used Castalia simulator to show comparison of their work with only static and with only dynamic TDMA mechanism [4]

According to the research paper of Siddharth Watwe et.al In Wireless sensor network clock synchronization is very useful. There are number of protocols developed to provide this requirement. When we use CSMA, this will not work well when two node tries to send synchronization message at the same time because there is possibility of collision. So the author has proposed the idea of TDMA based clock synchronization. They have simulated their result by using Castalia network simulator, according to result the work performs synchronization in very less period of time [5]

Another important work related to energy consumption and delay is proposed by author Majid Abbasy et.al Use of hardware which requires minimum energy is a useful way of minimizing energy consumption. According to the author in their work proper position of sink node with respect to other nodes.This author try to do this job for single sink node. The main idea in their work is finding optimal position of sink This is very useful for finding how geometric position of sink node effects on the performance of WSN such as performance related to energy and delay. This work is suitable for query based application [6].

Another important work is proposed by author Shuguo Zhuo et.al in their work they have tried to take advantage of both CSMA and TDMA When traffic density is high extra TDMA slots are allocated and when load is minimum slots are also minimum. Their proposed protocol is best for energy conservation but also it provides high throughput. The name of their protocol is iQueue-MAC. According to author In current WSN research maintaining good throughput and minimum delay is very important with low duty cycle protocols .iQueue-MAC is an improved version of QueueMAC [7].

QoS is very important for critical applications in wireless sensor network; author has proposed work to give QoS types of requirements. Mission critical applications such as industrial automation requires guaranteed delivery of data with only acceptable latency .Critical applications required updates generally in between time period of $10-250 \mathrm{~ms}$ so authors work is very useful to improve quality of service in the applications such as industrial automation[8].

Work proposed by author is also an important work related to the use of TDMA in applications where time is an important issue. They have proposed a protocol based on TDMA to provide energy efficiency with minimum delay. Here nodes are only active for period of data communication and at other time nodes are in sleeping mode.NS2 simulator is used to show performance of the system and comparison with the protocols not using SMEAR protocol . They have given SMEAR name to their protocol its meaning is slot management based energy aware routing for the applications where time is important . This method provides transfer of data between source node and sink node [9].It is not based on only single path here more than one paths are used for data communication and TDMA is used for medium access control .SMER works as both MAC protocol as well as routing protocol, because it uses TDMA as a medium access protocol in addition each node selects its best path having high energy available so single protocol performs routing as well as medium access job[9].

In work [10] TDMA is used for data transmission and in addition concept of tree is used. It is very useful work for energy consumption and load balancing .Here author have selected square area as an area to be monitor and here sensor nodes are distributed randomly. They assume that they have single base station away from our monitoring area .Sensor nodes can work till they have sufficient energy, so energy of nodes is limited. Here sensor nodes and base station are stationary. Here assumed that base station has no any energy limitations only sensor nodes have energy limitations. They are using sensor nodes having power control mechanism because of that any sensor node can change its power level according to requirement and can communicate with base station directly. Each node can get its position using any position related algorithm. For simplicity here author have provide a unique identity to each sensor node.

Here base station can select a node as root and sends its information to the remaining nodes now to transmit data to this root node network creates its path dynamically by creating tree of nodes in very less time and consuming minimum energy. Each time new path i.e. new tree is selected 
for balancing load for energy efficiency [10]. In work [11] authors used concept of clustering for better performance and for energy efficiency .Here threshold value is used for creation of clusters. This work used combination of both clustering and tree constructing for better performance. There results shows that the work balances load related to energy effectively and life of network is improved. Nodes selected as parent node in previous nodes may not be used for next round because new dynamic tree will contain new nodes for data transmission. Here nodes which are not involved in data transmission will go to the sleep state and they will not consume any energy. So here author has used combination of two methods for load balancing [11].

\section{COMPARISON OF ABOVE MENTIONED WORK}

Work presented in [1] is highly energy efficient and with minimum latency because of there is minimum contention and collision because of back off method. This work is developed for single hop and can be improved for multi hope. It is decentralized for dynamic environment. Author of work [2] has concentrated on providing QoS such as high throughput, minimum latency and reliability .their packet delivery ratio is better than previous 802.15.4. MAC protocol .Work [1] is based on single protocol but [2] is hybrid of TDMA and CSMA for improving QoS. Work [3] used another approach, according to their results the work produce TDMA schedule of minimum length and in minimum time to minimize correlated contention. Work[4]takes advantage of both static scheduling and dynamic scheduling to improve performance and runtime performance is improved .Work[5]focuses on clock synchronization and reduces collision between clock synchronization messages and synchronization is performed in very less period of time because for message passing purpose TDMA is used. Work[6] is based on position of the sink ,we can achieve better performance on energy efficiency and delay in query based applications minimization using proper position of sink .Like other work provided in this paper this work is different because it is not protocol base ,it is depends on proper position of the sink. Work[7]is based on adaptive duty cycle according to traffic load when load is less ,less amount of time slots are allocated and when traffic is high more number of slots are allocated for providing tradeoff between throughput and energy .combination of work[6] and[7 ]will provide better output in [8]cross layer improvement is provided in routing layer and in medium access layer for high Qos. Combination of this method with [5] will provide more effective system .In SMEAR TDMA is used for energy aware slot management purpose for providingbeater PRR ratio to improve Qos. here delay guarantee is provided in an energy efficient way. Finally we can say that by trying to combine different protocols and different methods mentioned in above papers we can create more and more better system in terns of Qos and energy efficiency. Work[10] is most different work than all the above work because it uses tree based structure for data communication and each time for communication new tree structure is selected having nodes with maximum energy level .Because of this load is properly balanced and energy conservation is achieved. Delay minimization is also achieved because all the nodes sends data in same TDMA slot and tree structure is generated dynamically in very less time period [10] .Table 1 shows this comparison in proper table format

Table 1: Comparison of application of TDMA in WSN.

\begin{tabular}{|c|c|c|c|c|c|c|c|}
\hline Protocol & $\begin{array}{l}\text { Energy } \\
\text { Awareness }\end{array}$ & $\begin{array}{l}\text { Contention } \\
\text { based }\end{array}$ & Qos & $\begin{array}{l}\text { Control } \\
\text { Packets } \\
\text { Required }\end{array}$ & $\begin{array}{l}\text { Timeliness } \\
\text { \&latency }\end{array}$ & $\begin{array}{l}\text { Pure } \\
\text { TDMA }\end{array}$ & Distributed \\
\hline LOCALL[1] & $\begin{array}{l}\text { Yes(Minimum } \\
\text { Collision due } \\
\text { to bakeoff } \\
\text { method) }\end{array}$ & $\begin{array}{l}\text { For Clock } \\
\text { Synchronizati } \\
\text { on }\end{array}$ & YES & $\begin{array}{l}\text { Initially fake } \\
\text { packet for Slot } \\
\text { accessing }\end{array}$ & $\begin{array}{l}\text { Low(Minimum } \\
\text { contention } \\
\text { because of fake } \\
\text { data) }\end{array}$ & YES & YES \\
\hline F-MAC[2] & YES & $\begin{array}{l}\text { Minimized for } \\
\text { QoS }\end{array}$ & $\begin{array}{l}\text { YES(M } \\
\text { aximum } \\
\text { ) }\end{array}$ & $\begin{array}{l}\text { YES(CSMA is } \\
\text { used) }\end{array}$ & Low & $\begin{array}{l}\text { TDMA } \\
+ \text { CSMA }\end{array}$ & NA \\
\hline $\begin{array}{r}\text { RD- } \\
\text { TDMA(Random } \\
\text { Distributed)[3] }\end{array}$ & $\begin{array}{l}\text { Not } \\
\text { Considered }\end{array}$ & $\begin{array}{l}\text { Correlated } \\
\text { contention is } \\
\text { minimized }\end{array}$ & $\begin{array}{l}\text { Provide } \\
\mathrm{d}(\text { Sched } \\
\text { ule of } \\
\text { small } \\
\text { length } \\
\text { in } \\
\text { minimu } \\
\text { m time) }\end{array}$ & $\begin{array}{lr}\text { Used } & \text { for } \\
\text { negotiation } & \text { of } \\
\text { time slot } & \end{array}$ & $\begin{array}{l}\text { Depends on data } \\
\text { rate }\end{array}$ & YES & YES \\
\hline $\begin{array}{r}\text { DSC(Distributed } \\
\text { Schedule }\end{array}$ & $\begin{array}{l}\text { Not } \\
\text { considered }\end{array}$ & $\begin{array}{l}\text { For clock } \\
\text { synchronizatio }\end{array}$ & $\begin{array}{l}\text { Run } \\
\text { Time is } \\
\text { minimiz }\end{array}$ & $\begin{array}{lr}\text { In } & \text { Static } \\
\text { TDMA } & \text { for } \\
\text { synchronizatio }\end{array}$ & $\begin{array}{l}\text { Latency is } \\
\text { minimized(Static } \\
+\quad \text { Dynamic }\end{array}$ & YES & YES \\
\hline
\end{tabular}




\begin{tabular}{|c|c|c|c|c|c|c|c|}
\hline Compaction)[4] & & $\mathrm{n}$ & ed & $\mathrm{n}$ & Scheduling) & & \\
\hline $\begin{array}{r}\text { TDMA clock } \\
\text { synchronization[5 } \\
]\end{array}$ & $\begin{array}{l}\text { Yes(For Clock } \\
\text { synchronizatio } \\
\text { n) }\end{array}$ & $\begin{array}{l}\text { Initially } \\
\text { CSMA used } \\
\text { for clock } \\
\text { synchronizatio } \\
n\end{array}$ & Medium & $\begin{array}{l}\text { Used for } \\
\text { synchronizatio } \\
n\end{array}$ & Not considered & $\begin{array}{l}\text { CSMA } \\
\& \text { TDM } \\
\text { A }\end{array}$ & YES \\
\hline $\begin{array}{l}\text { Single Sink } \\
\text { Mobility[6] }\end{array}$ & $\begin{array}{lr}\text { Position } & \text { of } \\
\text { sink } & \text { can } \\
\text { improve } & \\
\text { energy } & \\
\text { efficiency } & \end{array}$ & $\begin{array}{ll}\text { Delay } & \text { is } \\
\text { minimized } & \end{array}$ & $\begin{array}{l}\text { Only } \\
\text { Energy } \\
\text { consider } \\
\text { ed }\end{array}$ & $\begin{array}{l}\text { Qos can be } \\
\text { improved } \\
\text { adjusting sink } \\
\text { position }\end{array}$ & $\begin{array}{l}\text { Direct Diffusion } \\
+ \text { TDMA }\end{array}$ & NA & YES \\
\hline iQMAC[7] & $\begin{array}{l}\text { Improved } \\
\text { using duty } \\
\text { cycle }\end{array}$ & $\begin{array}{l}\text { CSMA is } \\
\text { used }\end{array}$ & $\begin{array}{l}\text { High } \\
\text { through } \\
\text { put }\end{array}$ & $\begin{array}{l}\text { Yes because of } \\
\text { CSMA }\end{array}$ & Minimum delay & $\begin{array}{l}\text { TDMA } \\
+ \text { CSMA }\end{array}$ & YES \\
\hline $\begin{array}{r}\text { Cross Layer } \\
\text { MAC \& routing } \\
\text { approach[8] }\end{array}$ & $\begin{array}{l}\text { Only QoS is } \\
\text { considered }\end{array}$ & $\begin{array}{l}\text { Only For time } \\
\text { synchronizatio } \\
\mathrm{n}\end{array}$ & $\begin{array}{l}\text { High } \\
\text { Qos(Del } \\
\text { ay } \\
\text { guarant } \\
\text { y) }\end{array}$ & $\begin{array}{l}\text { Only For time } \\
\text { synchronizatio } \\
\mathrm{n}\end{array}$ & $\begin{array}{lr}\text { Minimized } & \text { using } \\
\text { TDMA } & \text { and } \\
\text { routing tree } & \end{array}$ & $\begin{array}{l}\text { TDMA } \\
+ \\
\text { Routing } \\
\text { protocol } \\
\mathrm{s}\end{array}$ & YES \\
\hline $\begin{array}{r}\text { SMEAR(Slot } \\
\text { Aware Based } \\
\text { Energy Aware } \\
\text { Routing)[9] }\end{array}$ & $\begin{array}{l}\text { Improved(Mul } \\
\text { tiple paths are } \\
\text { used) }\end{array}$ & $\begin{array}{l}\text { Only For time } \\
\text { synchronizatio } \\
\mathrm{n}\end{array}$ & $\begin{array}{l}\text { Better } \\
\text { PRR \& } \\
\text { No of } \\
\text { packets } \\
\text { received }\end{array}$ & $\begin{array}{l}\text { Only For time } \\
\text { synchronizatio } \\
\mathrm{n}\end{array}$ & $\begin{array}{l}\text { Minimum PRR is } \\
\text { Improved }\end{array}$ & YES & YES \\
\hline
\end{tabular}

\section{CONCLUSION ANF FUTURE SCOPE.}

In wireless sensor network TDMA is very effective in order to provide energy conservation and for providing Qos requirements .according to our above survey there is no any single solution for energy conservation and Qos. Solution is depends on our requirements and objectives. We should use combination of different technics with TDMA and cross layer performance improvement technics(CSMA + TDMA) are also very useful to provide optimal solution. We know TDMA is MAC protocol, when we use MAC protocols with routing protocol, we can achieve better QoS and we can improve load balancing using proper routing protocol.

\section{ACKNOWLEDGMENTS}

This work is supported by K.J.College of Engineering and Management Research .I would like to thank my project guide and P.G coordinator for proper guidelines. I would also like to thank all other staff members of my college for their support.

\section{REFERENCES}

[1] Domenico De Guglielmo ,GiuseppeAnastasi ,Marco Conti, "A Localized Slot Allocation Algorithm for Wireless Sensor Networks", Ad Hoc Networking Workshop (MED-HOC-NET), Ajaccio, IEEE june 2013.

[2] Vivek S. Deshpande,Dattatray S. Waghole,"Performance Analysis of FMAC in Wireless SensorNetworks", Wireless and Optical Communications Networks (WOCN),Vijayawada,IEEEseptember 2014
[3] AshutoshBhatia , R. C. Hansdah ,"RD-TDMA: A Randomized and Distributed TDMAScheduling for Correlated Contention in WSNs",Advanced Information Networking and Applications Workshops (WAINA) Victoria BC May 2014

[4] Ashutosh Bhatia and R. C. Hansdah," A Fast and FaultTolerant Distributed Algorithm forNear-Optimal TDMA Scheduling in WSNs", Distributed Computing in Sensor Systems (DCOSS),Marina Del Rey, CA,IEEE May 2014

[5] SiddharthWatwe, Ashutosh Bhatia and R. C. Hansdah, "A Design for Performance Improvement of ClockSynchronization in WSNs using a TDMAbasedMAC Protocol", Advanced Information Networking and Applications Workshops (WAINA),Victoria, BC May 2014

[6] MajidBayaniAbbasy,Luis Miguel LópezOrdóñez, "Single-Sink Mobility Performance Analysis on a Wireless Sensor Networks",Advanced Information Networking and Applications Workshops (WAINA), Barcelona ,IEEE March 2013

[7] ShuguoZhuo, Zhi Wang, Ye-Qiong Song, Zhibo Wang and Luis Almeida," iQueue-MAC: A Traffic Adaptive duty-cycled MAC", Sensor, Mesh and Ad Hoc Communications and Networks (SECON), New Orleans, LA,june 2013

[8] Felix Dobslaw, Tingting Zhang, Mikael Gidlund,“QQoS Assessment for Mission-critical Wireless Sensor 
International Journal of Computer Applications (0975 - 8887)

Volume 144 - No.1, June 2016

Network Applications", Local Computer Networks (LCN) Sydney, NSW ,IEEE,OCT 2013

[9] Vijayalakshmi A, P. VanajaRanjan, "Slot Management based Energy Aware Routing (SMEAR) for Wireless Sensor Networks",Computing, Communication and Applications (ICCCA), Dindigul, Tamilnadu,IEE ,Feb 2012

[10] Zhao Han, Jie Wu, Member, IEEE, Jie Zhang, Liefeng Liu, and KaiyunTian,"A General Self-Organized Tree-
BasedEnergy-Balance Routing Protocolfor Wireless Sensor Network",Nuclear Science, IEEE Transactions ,IEE April 2014

[11] Kyung Tae Kim, Man Youn Kim, JiHyeon Choi, Hee Yong Youn,"An energy efficient and optimal randomized clustering for wireless sensor networks", 16th IEEE/ACIS International Conference, Takamatsu, Japan,june 2015 